\title{
EVALUASI SARANA DAN PRASARANA PEMBELAJARAN JURUSAN TEKNIK KOMPUTER JARINGAN MENGGUNAKAN MODEL CIPP DI SMK Negeri 2 PAYAKUMBUH
}

\author{
Rahmi Oktarina ${ }^{1}$ \\ Program Studi Pendidikan Teknologi Kejuruan \\ FT Universitas Negeri Padang \\ Email:amy_101090@yahoo.co.id
}

\begin{abstract}
This article was a study about the implementation of the learning facilities and infratructures in SMKN 2 Payakumbuh in its relationship to the prior low achievement of students in some courses in Computer Network Engineering department. Evaluation method used was the context, input, process, and product (CIPP) that included in a mixed method research. Sources of qualitative data obtained from the vice headmaster of facilities and infrastructure of SMKN 2 Payakumbuh, head of Computer Network Engineering department, head of the Computer Network Engineering lab and the teachers in that department.. The quantitative data were taken from students in XI TKJ class that consisted of 32 people. The research indicated that context component is in adequate category (73.71\%); the Input component is in adequate category (76.79\%); the Process component is in adequate category (78.06\%) and the Product component is also in adequate category (79.58\%). Due to all of components were in adequate category, it was suggested to conduct the appropriate improvement to improve the students achievements in thoses Computer Network Engineering courses.
\end{abstract}

Keyword : Evaluasi Program, CIPP, Facilities and Infrastructure Learning.

\section{PENDAHULUAN}

Prasyarat utama guna mencapai tujuan pendidikan SMK seperti yang diamanatkan pada bab $\mathrm{V}$ pasal 26 ayat (3) PP 19 tahun 2005 tentang Standar Nasional Pendidikan adalah terpenuhinya kelengkapan sarana dan prasarana yang memenuhi standar. Kelengkapan sarana dan prasarana pada sekolah kejuruan akan memperlancar segala aktivitas, terutama proses kegiatan pembelajaran bagi peserta didik, yang pada akhirnya akan meningkatkan kualitas lulusan. Standar kompetensi lulusan pada satuan pendidikan sekolah menengah kejuruan bertujuan untuk meningkatkan kecerdasan, pengetahuan, kepribadian, akhlak mulia, serta keterampilan untuk hidup mandiri. Untuk menjamin terwujudnya standar kompetensi lulusan tersebut, diperlukan kelengkapan sarana dan prasarana yang memenuhi standar minimal yang dibutuhkan. Berdasarkan karakteristik pendidikan kejuruan, penyelenggaraannya harus didukung oleh sarana dan prasarana yang memadai baik untuk kepentingan pendidikan dan pengajaran, penelitian, 
serta untuk pengabdian pada masyarakat (Sonhadji, 2002:5). Ketersediaan sarana dan prasarana yang memadai akan dapat mencapai tujuan tingkat satuan pendidikan sekolah kejuruan. Dengan adanya sarana dan prasarana yang memadai, proses kegiatan pembelajaran akan berjalan dengan baik dan lancar, serta mengembangkan bakat dan minat peserta didik.

Sekolah Menengah Kejuruan Negeri 2 (SMKN 2) Payakumbuh adalah sebuah SMK bidang Teknologi yang terdiri dari beberapa bidang keahlian, salah satunya keahlian Teknik Komputer Jaringan di mana proses belajar mengajar terdiri atas sekitar $30 \%$ teori dan $70 \%$ praktik. Dengan demikian, kebutuhan akan sarana dan prasarana yang memadai untuk praktik sangat tinggi. Oleh karena itu, informasi mengenai sarana dan prasarana yang dimiliki oleh SMKN 2 Payakumbuh tersebut perlu diketahui.

Berdasarkan observasi awal pada bulan Maret 2015 yang telah dilakukan di jurusan Teknik Komputer Jaringan (TKJ) SMKN 2 Payakumbuh, sarana dan prasarana pembelajaran masih memperlihatkan berbagai kendala dalam pembelajaran pada jurusan TKJ. Sarana praktik yang belum memenuhi kriteria pemakaian, jumlah dan kebutuhan siswa. Hal ini terlihat dari keterbatasan alat seperti hanya tersedia 20 komputer untuk \pm 30 orang siswa, fasilitas pendukung seperti jumlah kursi, meja dan peralatan lainnya masih belum memenuhi kriteria pemakaian sesuai dengan Permen Diknas no 40 Tahun 2008. Dapat dikatakan sarana prasarana di jurusan TKJ SMKN 2 Payakumbuh belum memadai sehingga menimbulkan kesulitan dalam proses belajar mengajar.
Kendala yang ditemui berdasarkan hasil observasi dan wawancara pada 18 Maret 2015 mengungkapkan belum tercapainya tujuan pembelajaran jurusan TKJ yang diduga diakibatkan belum optimalnya sarana dan prasarana dan belum terpenuhinya kebutuhan sarana dan prasarana pembelajaran. Ini terlihat dari dampaknya terhadap hasil belajar siswa khususnya dibidang praktek menjadi rendah.

Tabel. 1. Hasil Belajar Praktek Siswa Jurusan TKJ Semester Genap Tahun Pembelajaran 2014/2015

\begin{tabular}{|c|c|c|c|c|}
\hline \multirow{2}{*}{ No } & \multirow{2}{*}{ Kelas } & \multirow{2}{*}{$\begin{array}{c}\text { Jumlah } \\
\text { Siswa }\end{array}$} & \multicolumn{2}{c|}{ Hasil } \\
\cline { 3 - 5 } & & $\begin{array}{c}\text { \%elajar } \\
\mathbf{8 0}\end{array}$ & $\begin{array}{c}\text { \% } \\
\mathbf{8 0}\end{array}$ \\
\hline 1 & $\begin{array}{c}\text { Kelas } \\
\text { X }\end{array}$ & 31 & 58,06 & 41,95 \\
\hline 2 & $\begin{array}{c}\text { Kelas } \\
\text { XI }\end{array}$ & 32 & 59,37 & 40,63 \\
\hline \multicolumn{3}{|c|}{ Rata-rata } & 58,71 & 41.29 \\
\hline
\end{tabular}

Sumber: Guru SMK N 2 Payakumbuh

Data tabel 1. menunjukkan bahwa rata-rata hasil belajar siswa pembelajaran jurusan TKJ sebagian masih rendah dan belum memenuhi Kriteria Ketuntasan Minimum (KKM) yang telah ditetapkan oleh sekolah. Rendahnya hasil belajar praktek siswa pada mata pelajaran produktif jurusan Teknik Komputer Jaringan dapat dipengaruhi oleh berbagai komponen pendukung proses pembelajaran.

Dari hasil wawancara dengan kepala bengkel bidang keahlian TKJ pada 18 Maret 2015 terungkap bahwa beberapa orang guru yang mengajar pada jurusan TKJ belum memiliki kualifikasi akademik yang sesuai dengan jurusan TKJ ini. Berdasarkan dari data observasi lapangan ditemukan kurang sesuainya antara ijazah yang dimiliki dengan bidang 
studi yang diajarkan sehingga dalam proses pembelajaran guru kesulitan melengkapi bahan ajar dan modul pembelajaran yang berkaitan dengan Jurusan TKJ. Hal ini bertentangan dengan pasal 29 ayat 4 pada Peraturan Pemerintah Nomor 19 tahun 2005 tentang Standar Nasional Pendidikan yang berbunyi: "seorang tenaga pendidik pada sekolah menengah kejuruan/sederajat harus memiliki kualifikasi akademik yaitu: minimum Diploma empat (D-IV) atau Sarjana (S1), latar belakang pendidikan tinggi dengan program pendidikan yang sesuai dengan mata pelajaran yang diajarkan/diampu, memiliki sertifikat profesi guru untuk SMK/MAK yang diperoleh dari program studi yang terakreditasi”.

Salah seorang guru jurusan TKJ menjelaskan kurang aktifnya siswa disebabkan kurangnya sarana dan prasarana di laboratorium TKJ. Siswa dibagi menjadi beberapa kelompok yang terdiri dari 3-4 orang dalam 1 (satu) kelompok belajar tetapi tidak semua siswa aktif dan kreatif dalam proses pembelajaran. Minat dan motivasi yang kurang karena siswa hanya terpaku pada penyampaian dari guru. Selain itu sarana dan prasarana laboratorium jurusan TKJ yang ada di SMKN 2 Payakumbuh untuk penggunaan laboratoriumnya bersifat multifungsi, selain sebagai laboratorium komputer untuk kegiatan praktek siswa juga dijadikan sebagai sarana dan prasarana penyelenggaraan administrasi kantor jurusan TKJ.

SMKN 2 Payakumbuh pada proses pembelajaran juga menggunakan kurikulum 2013 tetapi proses pembelajaran masih mengacu seperti penggunaan kurikulum KTSP. Kurikulum 2013 yang menuntut sesuainya antara tujuan dari dengan kondisi pembelajaran yang menuntut siswa untuk aktif dan kreatif masih belum terjadi. Siswa masih terfokus sebagai penerima imformasi dari guru, dan guru belum aktif dan belum mampu dalam mencari dan mengembangkan materi pembelajaran seperti hardcopy bahan ajar, BSE (Buku Sekolah Elektronik). Dalam menyiapkan perangkat pembelajaran, pedoman guru hanya silabus, padahal guru juga dituntut kreatifitasnya untuk mencari dan mengembangkan perangkat pembelajaran lainnya.

Perbaikan yang terus menerus dalam proses pembelajaran harus terus diupayakan. Salah satu tahapan yang dilakukan agar terjadi peningkatan mutu pembelajaran adalah dengan melakukan evaluasi terhadap program pembelajaran. Tayibnapis (2008:9) menyatakan, " program adalah segala sesuatu yang dicoba lakukan seseorang dengan harapan akan mendatangkan hasil atau pengaruh. Widoyoko (2012:9) menyatakan bahwa "evaluasi program merupakan rangkaian kegiatan yang dilakukan dengan sengaja dan secara cermat untuk mengetahui tingkat keterlaksanaan atau keberhasilan suatu program dengan cara mengetahui efektifitas masingmasing komponen baik terhadap program yang sedang berjalan maupun yang telah berlalu". Menurut Suharsimi (2009:108) langkah-langkah evaluasi program antara lain sebagai berikut. Pertama, persiapan evaluasi program yang berupa penyusunan rencana evaluasi, penyusunan instrumen evaluasi, validasi instrumen evaluasi, menentukan jumlah sampel yang diperlukan dalam kegiatan evaluasi, dan penyamaan persepsi antara evaluator sebelum pengambilan data. Kedua, pelaksanaan evaluasi program yang dilakukakan dengan pengambilan data dengan tes, pengambilan data dengan observasi, 
pengambilan data dengan angket, pengambilan data dengan wawancara.

Evaluasi program pendidikan terdiri dari berbagai model yang digunakan. Penelitian ini menggunakan model evaluasi CIPP (contect, input, process, product) yang yang dikembangkan oleh Daniel Stufflebeam sebagai panduan dalam mengevaluasi program prakerin. Peneliti memilih model evalusi CIPP, sebab "model evaluasi CIPP lebih komprehensif jika dibandingkan dengan model evaluasi lainnya, karena objek evaluasi tidak hanya pada hasil semata tetapi juga mencakup konteks, masukan, proses, dan hasil" (Widoyoko, 2012:184).

Evaluasi program sarana dan prasarana pembelajaran di SMK sangat diperlukan, agar dapat dilakukan penyesuaian dan pembenahan secara berkelanjutan. SMK N 2 Payakumbuh belum pernah melakukan evaluasi program sarana dan prasarana pembelajaran, sehingga perlu dilakukan penelitian evaluasi mengenai program sarana dan prasarana pembelajarandengan model CIPP untuk mengetahui bagaimana pelaksanaan program tersebut dari berbagai aspek.

Berdasarkan permasalahan yang ada tersebut, maka dilakukanlah penelitian dengan judul Evaluasi Sarana dan Prasarana Pembelajaran di SMKN 2 Payakumbuh, yang bertujuan untuk mendeskripsikan sarana dan prasarana jurusan teknik komputer jaringan di SMK N 2 Payakumbuh dari berbagai aspek, seperti konteks, input, proses, serta hasil dari pelaksanaan program tersebut.

\section{METODE}

Jenis penelitian yang digunakan pada penelitian ini adalah penelitian evaluasi dengan model CIPP (Context, Input, Pricess, Product). Metode penelitian yang digunakan adalah metode kombinasi (Mixed Method Research), dengan model campuran berimbang (Concurrent Triangulation). Metode penelitian kombinasi campuran berimbang ini lebih menarik karena peneliti dapat mengumpulkan dua macam data (kualitatif dan kuantitatif) secara simultan, dalam satu tahap pengumpulan data. Dengan demikian data yang ditemukan menjadi lebih lengkap dan akurat.

Tempat penelitian adalah SMK Negeri 2 Payakumbuh yang beralamat di Jl. Soekarno Hatta/ Anggrek 1 Kec. Payakumbuh Barat kota Payakumbuh. Sekolah yang berdiri pada tahun 1961 merupakan sekolah yang memiliki peminat yang selalu meningkat disetiap tahunnya dan sudah pernah mendapat bantuan dari bank dunia atau lebih dikenal dengan ABD Invest Sekolah tersebut belum pernah melakukan evaluasi sarana dan prasarana pembelajaran $\mathrm{Hal}$ ini menjadi pertimbangan peneliti dalam pemilihan lokasi penelitian.. Waktu penelitian dilaksanakan pada bulan Juli 2015 sampai dengan selesai.

Data kualitatif pada penelitian ini diperoleh dari Wakasek Sarana dan Prasarana, Ketua Jurusan TKJ, kepala bengkel TKJ dan guru guru TKJ. Teknik pengambilan sampel adalah dengan teknik purposive, dimana peneliti memilih informan menurut kriteria tertentu yaitu informan yang mengerti dengan topik Sarana dan Prasarana Pembelajaran, serta dianggap kredibel untuk menjawab masalah penelitian. Data kuantitatif diperoleh dari siswa kelas XI yang berjumlah 32 siswa.

Teknik pengumpulan data kualitatif menggunakan teknik 
wawancara dan studi dokumentasi. Teknik wawancara kemudian dianalisis dengan cara reduksi data, display data, serta penarikan kesimpulan. Pengumpulan data kuantitatif diperoleh dengan teknik pengambilan angket; angket ini sebelum dipakai telah terlebih dahulu diuji validitas dan reliabilitasnya. Data dariangket kemudian dianalisis untuk mendapatkan data mean, median, mode, standar deviasi, frekuensi, dan persentase dengan menggunakan program SPSS versi 16. Data yang telah diperoleh dideskripsikan dengan tujuan melihat Tingkat Pencapaian Responden (TPR) pada masing-masing variabel dan indikator dan ditentukan kategorinya. TPR dihitung dengan rumus sebagai berikut,

$$
\mathrm{TPR}=\frac{\sum \text { skor }}{\text { Skala tertinggi }} \times 100 \% .
$$

(Syahron Lubis, 2011: 87)

Hasil analisis tersebut kemudian dikelompokan, dibedakan, dan dicari hubungan antara satu data dengan data lainnya, sehingga dapat diketahui apakah kedua temuan tersebut saling memperkuat, saling memperlemah, atau bertentangan. Gabungan hasil analisis ini dibuat berdasarkan masingmasing komponen model evaluasi CIPP, yaitu konteks, input, proses, dan produk, kemudian diambil kesimpulan. Kesimpulan diambil berdasarkan masing-masing komponen CIPP dengan memasukan rata-rata persentase tingkat pencapaian responden dalam bentuk angka, dan ditentukan kategorinya, kemudian dilengkapi dengan hasil analisis data kualitatif untuk mendukung serta menjelaskan temuan analisis kuantitatif.

\section{HASIL DAN PEMBAHASAN \\ a. Komponen konteks (context)}

Pada komponen konteks terdapat tiga indikator yaitu tujuan pembelajaran, kebutuhan dan masalah sarana dan prasarana. Berdasarkan analisis masingmasing didapat kesimpuln yang dimuat dalam tabel 2.

Tabel. 2. Analisis Gabungan Komponen Konteks

\begin{tabular}{|c|c|c|}
\hline Indikator & $\begin{array}{c}\text { Analisis } \\
\text { Kuantitatif }\end{array}$ & $\begin{array}{c}\text { Analisis } \\
\text { Kualitatif }\end{array}$ \\
\hline $\begin{array}{l}\text { Ketercapaian } \\
\text { Tujuan } \\
\text { pembelajaran }\end{array}$ & $70.87 \%$ & $\begin{array}{l}\text { hasil belajar teori } \\
\text { siswa sudah } \\
\text { meningkat tetapi } \\
\text { belum dengan } \\
\text { hasil praktek } \\
\text { siswa. }\end{array}$ \\
\hline $\begin{array}{l}\text { Kebutuhan } \\
\text { Sarana dan } \\
\text { prasarana } \\
\text { pembelajaran }\end{array}$ & $76.25 \%$ & $\begin{array}{l}\text { komputer } \\
\text { jaringan masih } \\
\text { belum } \\
\text { kebutuhan } \\
\text { jumlah dan } \\
\text { dalam siswa } \\
\text { pembelajaran. } \\
\text { sehingga waktu } \\
\text { praktek menjadi } \\
\text { lebih singkat }\end{array}$ \\
\hline $\begin{array}{l}\text { Masalah Sarana } \\
\text { dan Prasarana } \\
\text { Pembelajaran }\end{array}$ & $74.00 \%$ & $\begin{array}{l}\text { Ketersediaan } \\
\text { sarana dan } \\
\text { prasarana belum } \\
\text { sepenuhnya } \\
\text { mendukung } \\
\text { pelaksanaan } \\
\text { kurikulum 2013, } \\
\text { Pemeliharaan } \\
\text { sarana } \\
\text { prasarana } \\
\text { dilaksanakan oleh } \\
\text { guru dibantu oleh } \\
\text { beberapa orang } \\
\text { siswa belum ada } \\
\text { tenaga ahli }\end{array}$ \\
\hline $\begin{array}{l}\text { Kesimpulan } \\
\text { analisis } \\
\text { komponen } \\
\text { Konteks }\end{array}$ & $\begin{array}{l}73.71 \% \\
\text { Cukup }\end{array}$ & $\begin{array}{l}\text { sudah cukup baik, } \\
\text { perlu adanya } \\
\text { perbaikan }\end{array}$ \\
\hline
\end{tabular}

b. Komponen Masukan (Input)

Pada komponen input, terdapat empat indikator. yaitu SDM guru, siswa, sarana dan prasarana, dan pembiayaan. Temuan penelitian dapat dilihat dalam tabel 3. . 
Tabel. 3. Analisis Gabungan Komponen Masukan

\begin{tabular}{|c|c|c|}
\hline Indikator & $\begin{array}{c}\text { Analisis } \\
\text { Kuantitatif }\end{array}$ & $\begin{array}{l}\text { Analisis } \\
\text { Kualitatif }\end{array}$ \\
\hline SDM guru & $71.56 \%$ & $\begin{array}{l}\text { ketidak sesuaian } \\
\text { antara mata } \\
\text { pelajaran yang } \\
\text { diajarkankan } \\
\text { dengan } \\
\text { kualifikasi } \\
\text { akademik } \\
\text { menjadikan } \\
\text { kurangnya } \\
\text { penguasaan } \\
\text { materi dan } \\
\text { kesulitan dalam } \\
\text { penggunaan } \\
\text { sarana dan } \\
\text { prasarana } \\
\text { pembelajaran. }\end{array}$ \\
\hline Siswa & $78.96 \%$ & $\begin{array}{lr}\text { Siswa } & \text { masih } \\
\text { terfokus } & \\
\text { penerima } & \\
\text { informasi } & \text { dari } \\
\text { guru dan belum } \\
\text { aktif } & \text { dalam } \\
\text { mencari materi } \\
\text { pembelajaran }\end{array}$ \\
\hline $\begin{array}{l}\text { Sarana dan } \\
\text { Prasarana }\end{array}$ & $75.71 \%$ & 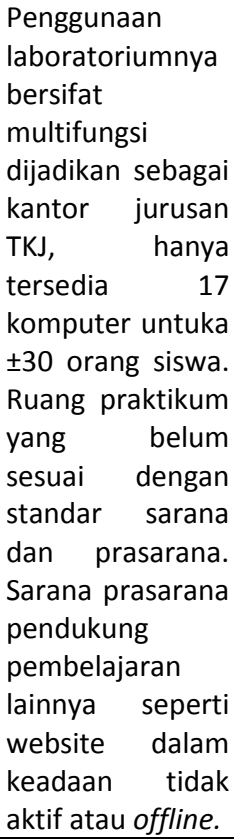 \\
\hline Pendanaan & $80.94 \%$ & $\begin{array}{l}\text { kebutuhan } \\
\text { sarana dan } \\
\text { prasarana yang } \\
\text { banyak sehingga } \\
\text { dana tersebut } \\
\text { tidak mencukupi } \\
\text { untuk pengadaan } \\
\text { jurusan teknik } \\
\text { komputer } \\
\text { jaringan karena }\end{array}$ \\
\hline
\end{tabular}

\begin{tabular}{|c|c|c|}
\hline & & $\begin{array}{l}\text { juga digunakan } \\
\text { untuk jurusan } \\
\text { yang lainnya. }\end{array}$ \\
\hline $\begin{array}{l}\text { Kesimpulan } \\
\text { analisis } \\
\text { komponen } \\
\text { masukan }\end{array}$ & $\begin{array}{c}76.79 \% \\
\text { Cukup }\end{array}$ & $\begin{array}{l}\text { Komponen } \\
\text { Masukan dalam } \\
\text { program sarana } \\
\text { dan prasarana } \\
\text { masih tergolong } \\
\text { cukup baik perlu } \\
\text { ditingkatkan lagi }\end{array}$ \\
\hline
\end{tabular}

\section{c. Komponen Proses (Proccess)}

Pada komponen proses, terdapat tiga indikator yaitu tahap perencanaan, tahap pengadaan, dan tahap pemanfaatan. Hasil temuan dapat dilihat dalam tabel 4 .

\section{Tabel. 4. Analisis Gabungan}

\section{Komponen Proses}

\begin{tabular}{|c|c|c|}
\hline Indikator & $\begin{array}{c}\text { Analisis } \\
\text { Kuantitatif }\end{array}$ & $\begin{array}{c}\text { Analisis } \\
\text { Kualitatif }\end{array}$ \\
\hline $\begin{array}{l}\text { Tahap } \\
\text { Perencanaan }\end{array}$ & $80.06 \%$ & 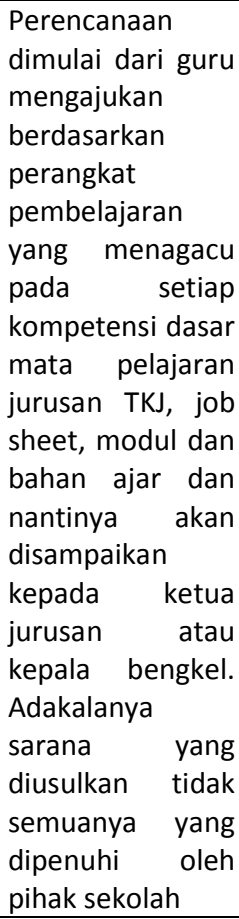 \\
\hline $\begin{array}{l}\text { Tahap } \\
\text { Pengadaan }\end{array}$ & $74.06 \%$ & $\begin{array}{l}\text { Pengadaan sudah } \\
\text { menyesuaikan } \\
\text { dengan plafon } \\
\text { anggaran sekolah } \\
\text { atau dana BOS, } \\
\text { Komite Sekolah } \\
\text { serta mendapat } \\
\text { bantuan dari } \\
\text { pemerintah. } \\
\text { Namun }\end{array}$ \\
\hline
\end{tabular}




\begin{tabular}{|l|l|l|}
\hline & & \multicolumn{2}{|l|}{ pengadaan } \\
sarana masih \\
terbatas, adapun \\
sumbangan yang \\
diterima oleh \\
pihak sekolah \\
harus dibagi \\
dengan jurusan \\
lain.
\end{tabular}

\section{d. Komponen Hasil (Product)}

Pada komponen Hasil, terdapat indikator Evaluasi hasil terhadap, yaitu peningkatan kompetensi kognitif, afektif, dan psikomotorik. Hasilnya dapat dilihat dalam tabel 5.

Tabel. 5. Analisis Gabungan Komponen Hasil

\begin{tabular}{|l|c|l|}
\hline Indikator & $\begin{array}{c}\text { Analisis } \\
\text { Kualitatif }\end{array}$ & \multicolumn{1}{|c|}{$\begin{array}{c}\text { Analisis } \\
\text { Kuantitatif }\end{array}$} \\
\hline Peningkatan & $81.88 \%$ & $\begin{array}{l}\text { memperluas } \\
\text { wawasan ilmu } \\
\text { pengetahuan } \\
\text { Kognitif } \\
\text { uma, dan secara } \\
\text { umum } \\
\text { meningkatkan } \\
\text { hasil belajar siswa }\end{array}$ \\
\hline
\end{tabular}

\begin{tabular}{|c|c|c|}
\hline $\begin{array}{l}\text { Peningkatan } \\
\text { Psikomotorik }\end{array}$ & $73.75 \%$ & $\begin{array}{l}\text { masih perlu } \\
\text { ditingkatkan lagi } \\
\text { seperti } \\
\text { keterampilan dan } \\
\text { skill siswa karena } \\
\text { antara nilai teori } \\
\text { dan praktek siswa } \\
\text { belum seimbang }\end{array}$ \\
\hline $\begin{array}{l}\text { Peningkatan } \\
\text { Afektif }\end{array}$ & $80.49 \%$ & $\begin{array}{l}\text { meningkatkan } \\
\text { kedisiplinan dan } \\
\text { tanggung jawab } \\
\text { siswa hanya } \\
\text { beberapa orang } \\
\text { saja yang perlu } \\
\text { diperhatikan }\end{array}$ \\
\hline $\begin{array}{l}\text { Kesimpulan } \\
\text { analisis } \\
\text { komponen } \\
\text { Hasil }\end{array}$ & $\begin{array}{c}78.71 \% \\
\text { Cukup }\end{array}$ & $\begin{array}{l}\text { Komponen hasil } \\
\text { dalam program } \\
\text { sudah cukup baik, } \\
\text { namun perlu } \\
\text { adanya perbaikan } \\
\text { untuk } \\
\text { meningkatkan } \\
\text { kompetensi } \\
\text { psikomotor siswa }\end{array}$ \\
\hline
\end{tabular}

\section{SIMPULAN DAN SARAN}

Berdasarkan analisis data dan pembahasan, maka dari penelitian hasil evaluasi terhadap Sarana dan Prasarana Jurusan TKJ di SMK Negeri 2 Payakumbuh dapat disimpulkan bahwa:

1. Komponen konteks dalam program sarana dan prasarana pembelajaran sudah cukup baik, namun perlu adanya perbaikan dari ketersediaan sarana prasarana yang belum memadai.

2. Komponen masukan dalam program sarana dan prasarana pembelajaran sudah cukup baik, ini dibuktikan dari kriteria Sumber Daya Manusia, sarana dan prasarana, serta pendanaan, yang ada di dalam harus diperbaiki secara keseluruhannya.

3. Komponen proses dalam program sarana dan prasarana pembelajaran sudah cukup baik, namun perlu adanya perbaikan pada tahap pengadaan jurusan TKJ, serta tahap pemanfaatan, yaitu dan belum 
adanya tenaga ahli untuk pemeliharaan sarana prasarana secara berkala.

4. Komponen Hasil dalam program sarana dan prasarana pembelajaran sudah cukup baik, pada kompetensi afektif dan kognitif siswa, sudah ada peningkatan. Namun perlu adanya perbaikan untuk meningkatkan kompetensi psikomotor siswa, dalam bentuk hasil praktek dan keterampilan siswa.

Ada beberapa saran yang penulis tujukan untuk berbagai pihak terkait Sarana dan Prasarana Pembelajaran di SMK Negeri 2 Payakumbuh. Antara lain:

1. Bagi siswa Sekolah agar meningkatkan pengadaan sarana prasarana dan ketersediaan dana yang lebih memadai sesuai dengan kebutuhan jurusan teknik komputer jaringan.

2. Sekolah menunjuk tenaga ahli yang diperlukan untuk pemeliharaan sarana dan prasarana secara berkala

3. Wakil kepala sekolah bidang sarana prasarana melengkapi kebutuhan sarana prasarana jurusan teknik komputer jaringan agar pembelajaran lebih kondusif dan lebih maksimal.

4. Guru jurusan teknik komputer jaringan lebih meningkatkan kompetensi yang seharusnya dimiliki oleh seorang guru, baik itu penguasaan materi dan sarana dan prasaranayang digunakan.

5. Siswa diharapkan aktif dan kreatif dalam mengembang ilmu yang telah dipelajari serta meningkatkan motivasi dalam belajarnya sehingga hasil yang akan di capai lebih masksimal.

\section{UCAPAN TERIMA KASIH}

Artikel diolah dari Tesis Rahmi Oktarina dengan judul Evaluasi Sarana dan Prasarana Pembelajaran Jurusan Teknik Komputer Jaringan di SMK Negeri 2 Payakumbuh. Selanjutnya penulis mengucapkan terimakasih kepada Kepala Sekolah dan Guru Teknik Komputer Jaringan SMK N 2 Payakumbuh yang telah berkenan meluangkan waktunya untuk membantu penulis dalam penyelesaian penelitian ini.

\section{DAFTAR RUJUKAN}

Peraturan Pemerintah Republik Indonesia Nomor 19 Tahun 2005 (http://kemenag.go.id/file/dokumen/ PP1905.pdf) diakses 20 maret 2015

Sonhadji, H.A. 2002. Alternatif Penyempurnaan Pembaharuan Penyelenggaraan Pendidikan di SMK. Makalah disajikan pada Studi tentang Pengkajian Pendidikan Kejuruan dan Teknologi, Depdiknas, Jakarta, 23 Oktober 2002.

Suharsimi Arikunto \& Cepi Safruddin. 2009. EvaluasiProgram Pendidikan, Panduan Teoritis Praktis Bagi Praktisi Pendidikan. Jakarta: BumiAksara.

Tayibnapis, Farida Yusuf.2008. Evaluasi program dan instrumen evaluasi untuk program pendidikan dan penelitian. Jakarta: Rineka Cipta.

Widoyoko, Eko Putro. 2012. Evaluasi Program Pembelajaran: Panduan Praktis Bagi Pendidik dan Calon Pendidik. Yogyakarta: Pustaka Pelajar. 